BROMTO-SODA

William Warner and Co.. Philadelphia.

The report states that an examination showed this product to contain caffein, tartrates, citrates, sodium bromid and sodium carbonate. "On notif ying the company of the requirements under the law with regard to labeling for bromids, we were assured that the product is now being labeled to comply with the law and labels were furnished which show that each tablespoonful contains thirty grains of sodium bromid and one grain of caffein, which wonld comply with the requirements of the drug law of this state."

\section{HAIR TONICS.}

Various hair tonics were examined, among them Danderine, which was found to contain ethyl alcohol, by volume, 10.5. When the makers were notified that it must be labeled for the per cent. of alcohol which it contained, they replied:

"Replying to yours of the first, will say that under the ruling which you have made we must decline to ship any more goods to North Dakota."

The people of North Dakota are certainly to be congratulated on being so efficiently protected from frauds.

\section{German Campaign Against "Patent Medicines."}

Germany has for some time adopted the practice of publishing a kind of biannual black list of remedies, against the sale of which very severe restrictions were put, says the British and Colonial Druggist. This course has not been found satisfactory in the opinion of Count v. Posadowsky, the home secretary, who, according to the Hamburger Nachrichten, has a new plan of procedure under consideration. The list which, if the present system were maintained, would be published in October of the current year, is said to comprise no fewer than 600 new proprietary medicines. Against the regulations now in force two objections are cited, the possibility of a dealer escaping their effects by altering his production in name and composition before the issue of a new list, and secondly, the tendency which the publication of these lists creates of regarding them as indicative of what does and what does not constitute a "patent medicine." The new bill to be shortly laid before the Bundesrat is to strike at the trade by a special and easily applied legal process; "patent medicine" boards are to be founded, in which medicine, pharmacy and chemical industry will be represented, and before which the "patentmedicine" manufacturer will have the opportunity of appearing. These boards will apparently be given the duty of investigating the merits of each individual preparation. It is not stated who is to bear the cost.

\section{Correspondence}

\section{The Country Doctor.}

Greeter, Coxo., July 14, 1906.

To the Editor:-In The Journal, May 19, there appeared an article by Dr. John G. Wilson, Montrose, Pa., entitled "The Country Doctor," which attracts attention, first, on account of its title, second, on account of its brevity. Its title appealed to those of us who labor under this cognomen, and in warm weather brevity is the soul of interest as well as the soul of wit. .As Dr. Wilson does not attempt to define the title "country doctor," or enumerate the country doctor's characteristics, it remains for those of us who have perused the article to decide if we are qualified to bear this honorable name. Unless we include in this category all who reside outside the limits of metropolitan cities and centers of learning, it is, perhaps, a rather difficult problem to draw a definite line of demarcation. Hospitals are found in many small towns and competent trained nurses are obtainable in practically all. The physician in the small town is as busy, on the whole, as his city brother and likely to see as many patients. Books, medical journals and office equipment are not difficult to secure in either location, and sureIy no one would presume to think that a private office or laboratory located in the tenth story is more conducive to mental astute. ness than one overlooking the cabbage patch. Notwithstanding these facts, the man in the small town is justly entitled to the name, and it is of him we may conclude that Dr. Wilson speaks. If we turn briefly to the profession of any city with which we are familiar we will find therein physicians of all grades of ability. Not all rise to the standard of Osler or Kelly, nor do many sink to the depths of the "specialist re. cently of Paris and Vienna." In the ranks of the country practitioners the same discrepancy exists. We have at times a Sims or a Mayo, more frequently capable toilers in the ranks and rarely the aforementioned criminal operator.

Dr. Wilson's appeal is certainly well timed and breathes the gospel of hope to the country physician who is anxious to render the best service to his patients. Not that the country doctor should attempt work with which he is unfamiliar; rather he should familiarize himself with this work in order that his advice may be both safe and sane. Dr. Wilson's remarks may be criticised or neglected by many who have no aptitude, ability or desire to render better or more skilled service to those seeking advice. Others wise in their day and generation may give timely heed to the words of the prophet: "The ordinary physician must become more competent or cease to exist. No one physician can do the best possible work in all lines of modern medical practice, but he may do better work in every field and the best work in almost every instance." If he desires to enlist in this progressive class, and has the ability and application to support his wishes, "he must embrace the opportunities freely given by the masters of the profession at their elinics," and "he must be determined to improve himself at every opportunity."

Charles B. Dyde, M.D.

The Gelatin Method of Preserving Specimens.

Boston, July 16, 1906.

To the Editor:-The title page of "Pathology and Treatment of Glaucoma" by Priestley Smith, published by Churchill, London, 1891, states that the volume is a revised publication. with additions, of the Erasmus Wilson lectures, delivered at the Royal College of Surgeons of England, in March, 1889. This is interesting in view of the claims for priority as regards the gelatin method of preserving specimens in Prof. Watters' letter in Tile Journal, A. M. A., July 14, 1906. Smith's method may be briefly described somewhat as follows: Fixation by the bichromate method, freezing, bisecting and em. bedding in a glycerin or gelatin jelly, the latter being prepared by soaking gelatin in water (1/8), melting, and after adding the white of an egg, boiling and filtering. Glycerin, 8 parts, and 60 drops of 10 per cent. carbolic acid is then added. At page 183 of this monograph it is stated in a footnote that: "The first suggestion of preserving specimens in glycerin jells was published by Nettleship in 1871 (Royal London Ophthalmic Hospital Reports VIII, page 225)." In an article published in the Royal London Ophthalmic Hospital Reports, August, 1880, on glaucoma, Smith mentions embedding specimens in glycerin jelly. During 1896-8 Dr. Charles H. Williams showed several specimens of eyes mounted according to the Priestley-Smith method, somewhat modified, at various society meetings, and at about the same time the method came into use at the laboratory of the Massachusetts Charitable Eye and Ear Infirmary, which was then under the direction of Dr. W. J. Daly and myself. The use of glycerin jelly for the preservation of sections for microscopic examination was considered, to my personal knowledge, a convenient method, a quarter of a century ago. Although found to have been superior to bichromate for fixation, I have made no mention of formalin or the Kaiserling solution, confining myself to the crude and inconvenient method of fixation so much in use at a time when ophthalmology was only beginning to receive recognition, nevertheless the suggestions of 1871 have resulted in the development of a method which to-day is evidently ap. preciated by the general pathologist as well as by the worker along special lines of investigation.

William Dudley Hall, M.D. 